\title{
Traveling Together? Navigating the Practice of Collaborative Engagement in Coast Salish Communities
}

\author{
Sarah Marie Wiebe, Kelly Aguirre, Amy Becker, Leslie Brown, Israyelle Claxton, \\ Brent Angell
}

\begin{abstract}
Academics widely understand participatory action research (PAR) to be relevant to communities, collaborative from project design to dissemination of results, equitable and participatory while also action-oriented in pursuit of social justice. In this article, we suggest that there is much need to address both the challenges and opportunities that researchers encounter when applying participatory tools within an Indigenous context. In September 2013, the University of Victoria research team began a transportation safety project in partnership with the University of Windsor and participating Indigenous communities across the country. This project entailed both quantitative and qualitative research methodologies, including a national survey in addition to community conversations, to promote community health and injury prevention. Responsible for outreach to coastal communities in British Columbia, the interdisciplinary research team employed PAR methodologies to address local and national transportation safety concerns ranging from booster seat use to pedestrian safety. In this paper, we ask: what can participatory approaches offer the study of community-engaged research (CER) with Indigenous communities? First, we assess the promises and perils of PAR for community-engaged research when working with Indigenous communities; second, we aim to demystify the process of PAR based on our experience working with the Tsawout First Nation to "Light up the Night" through participatory video with Indigenous youth; third, we reflect on what we learned in this process and discuss avenues for further research. Our submission entails a written article and accompanying videos that illuminate the creative approach to collaborative engagement with Indigenous communities.
\end{abstract}

KEYWORDS participatory action research; community engagement; Indigenous communities; participatory video; transportation safety

Research sometimes takes academics outside of the university setting and into communities. This journey involves encounters with "situated knowledges" and thus requires conceptual sophistication and methodological innovation (Haraway, 1988). In this article, we discuss and assess the promises and challenges of participatory action research (PAR) while collaborating with the Tsawout First Nation on understanding and reducing the risk of vehicle-related injuries and fatalities involving Indigenous peoples, which have serious socioeconomic implications for their communities. In general terms, PAR is widely understood as an approach that is 
relevant to communities, collaborative from project inception to the dissemination of results, equitable and participatory while also action-oriented in pursuit of social justice. There is much need to address both the challenges and opportunities that researchers encounter when applying participatory tools within an Indigenous context.

The impetus for this particular site of community engagement with the Tsawout First Nation stems from the work of Dr. Leslie Brown, former Director of the Institute for Studies and Innovation in Community University Engagement (ISICUE) at the University of Victoria, as a research collaborator on a national research network headed by Dr. G. Brent Angell, Principal Investigator, from the University of Windsor. Funded by AUTO21, which is an initiative of the Networks of Centres of Excellence (NCE) Secretariat of the Canadian Government, ISICUE's participation provided an opportunity for Indigenous peoples in the Province of British Columbia to have presence and voice in this nationwide research endeavour. The project's methodology is founded on PAR principles and tools selected to better understand the challenges faced with respect to vehicle-related injury prevention. Through community engagement, this project envisioned better understanding of how Tsawout community members define and address the transportation safety challenges they face. The PAR approach aims to be grounded in the knowledge, wisdom, and experience of Tsawout participants and their shared sociocultural worldview. As such, depending upon a particular community's need and interest, both qualitative and quantitative methodologies may be relevant in determining what is at issue and how best to move forward in resolving identified difficulties.

Using creative visual tools, ISICUE's BC-focused interdisciplinary research team ("the research team") applied the PAR methodology to partner with Indigenous communities in the hope that local concerns about vehicle injuries could be addressed, which in turn could contribute to a national conversation about injury prevention. In this paper, we ask: What can participatory approaches offer the study of community-engaged research (CER) with Indigenous communities in the context of the work done in British Columbia? First, we assess the opportunities and challenges that PAR methods bring to CER when working with the Indigenous communities we were engaged with; second, we aim to explain our experiences using PAR with the Tsawout First Nation to "Light up the Night" through participatory video with Indigenous youth; third, we reflect on what we learned in this process and discuss avenues for further research. Our submission entails a written article and accompanying videos that illuminate a creative approach to collaborative engagement with Indigenous communities based on our experience working on this project in British Columbia.

\section{Participatory Research and Ethical Engagement in Coast Salish Territory}

Situated on the territory of the Coast and Straights Salish people, the University of Victoria is located within and in relationship to surrounding Indigenous peoples, who view life as a part of a bio-psychosocial-cultural-spiritual-physical ecosystem. This ecosystem provides context, life, meaning, and knowledge on their particular relationship with the land, water, plants, and animals. As researchers affiliated with an academic institution, we acknowledge 
that our work is influenced by our position as visitors on the traditional territories of the WS'ANEC' (Saanich), Lkwungen (Songhees) and Wyomilth (Esquimalt) peoples of Coast and Straights Salish Nations. Collaborating ethically with local Indigenous communities requires recognition of the fact that academic institutions sit on Indigenous lands and territories from which many Indigenous peoples were displaced as a result of colonization. Understanding that as researchers we are implicated in oppressive relationships, it is imperative that we conceptualize our working and travelling together in our learning journeys as co-creators of knowledge founded on anti-oppressive practices and methodologies.

The University of Victoria has a long history of its researchers working collaboratively with Indigenous peoples and communities. An opportunity to build on those relationships by being a part of the network of researchers working on the vehicle injury prevention project was viewed as a positive way to collaborate promising practices aimed at furthering the wellbeing of Indigenous children, families and communities. Research in and with Indigenous communities necessitates awareness and commitment to principles of Ownership, Control, Access and Possession (OCAP) in addition to self-determination (NAHO, 2005). When conducting research projects, both the University of Windsor and the University of Victoria use protocol agreements with communities as a way to reflect their accountability to OCAP and to distinct communities and Nations. Beyond the specific agreement developed for the transportation safety project with Tsawout, the University of Victoria has an overarching collaborative agreement with the WS'ANEC' School Board, to which Tsawout is party, that sets out the relational principles between the university and the $\underline{\mathrm{W}} \mathrm{S}^{\prime} \mathrm{ANEC}$ ' communities. The WS'ANEC' - University of Victoria Collaborative Agreement articulates, in both English and SENĆO円EN languages, principles such as collaborative decision making, respect, transparency, excellence and honouring of cultural practices (2014). This agreement describes how we are going to be together. As such, it inspires and grounds our approach to PAR through our unique emphasis on CER. In addition, the agreement developed specifically for the transportation safety project in Tsawout describes what we are going to do together and how. This agreement guides our ethical practice.

Informed by PAR principles and practices, CER refers to a continuum of research approaches in which researchers work with, for, and alongside communities. It refers to speaking and partnering with rather than researching 'on' or speaking 'on behalf of'. The lengthy history of disembodied, extractive and objectifying research with Indigenous communities is now well documented (Smith, 1999; Strega \& Brown, 2015). CER aims to counter these conventions while taking citizens' experiences, narratives and stories seriously as a kind of evidence and truth in pursuit of social justice and change. In this respect, research serves as a tool of "resistance" to inequity and celebrates the "resurgence" of Indigenous knowledge (Strega \& Brown, 2015). The fabric of the research process itself can be a powerful anti-oppression tool oriented towards the interruption of injustices such as racism, colonialism and patriarchy. As Community-based Research Canada (CBRC) scholars and affiliates highlight, CER entails several crucial components: community relevance, research design, equitable participation and action and change (Ochocka \& Janzen, 2013; Wiebe \& Taylor, 2014). In general terms, this refers to 
involving collaborating communities in all stages of the research process from design right through to dissemination.

At its core, CER involving Indigenous engagement must build upon principles of respect, relationship-building, reflexivity, reciprocity. The project in British Columbia employed a PAR approach, through community engagement in accordance with the following principles (Tuck et al., 2008):

- There is transparency on all matters of the research;

- The research questions are co-constructed;

- The project design and design of research methods are collaboratively negotiated and constructed;

- The analysis is co-constructed;

- The products of the research are dynamic, interactive and are prepared and disseminated in collaboration.

Participatory methodologies are often seen as 'sister' approaches to Indigenous methodologies (Kovach, 2005). There are particular ethics and accountabilities that arise when researchers engage with Indigenous peoples and communities. Robina Thomas and Leslie Brown's Protocols of Dignity framework for working with Indigenous communities posits that the past, present and future are all connected in each moment (Thomas \& Brown, 2015). Understanding our individual and collective relationships to the past and future impacts how we choose to relate in the present. Our historical, current, and future relationship to colonization, for example, is evident in each research interaction. Holding relationships as the crux of CER with Indigenous peoples requires this critical approach. As a form of "critical reflexivity," engaging with dignity is necessarily complicated and uncomfortable as it forces us to critically self-reflect on our practices (Strega \& Brown, 2015). This informs our collaborative approach with members of the Tsawout First Nation.

Reducing injury from vehicle collisions is the overarching interest to the researchers on this project and stems from the systemic risks posed to the health and safety of Indigenous people living in reserve communities today. Infrastructure is vital to the health and well being of several communities in British Columbia and elsewhere. For instance, the 2006 Highway of Tears Symposium report draws attention to the numerous Indigenous women who have gone missing or been found murdered along a $724 \mathrm{~km}$. highway from Prince Rupert to Prince George, BC (Carrier Sekani Family Services, 2006). This report highlights the great need for safe transportation routes for the health and wellbeing of Indigenous communities and signals the need for further research on this crucial topic across the province and beyond. While traffic-related injuries and deaths are among the leading causes of death around the world and in Canada, Indigenous peoples are uniquely affected (WHO, 2012, StatsCan, 2011, UNICEF Canada, 2009). As Angell (2012) writes, it is not an over-stated fact that the health status of First Nations, Inuit and Métis people falls below that of the rest of the Canadian population. According to Health Canada (2011), and Pike MacPherson and McDonald (2010), injuries 
within First Nations communities are the leading cause of death, estimated at twice the national average. Furthermore,there is limited research focusing on vehicle driver, passenger, and pedestrian safety with this population (Angell 2012). Indeed, a Transport Canada (2003) study involving three First Nations communities in Manitoba revealed very low rates of childseat use, particularly in school-aged children. The First Nations and Inuit Children and Youth Injury Indicators Working Group noted that vehicle crashes are the main cause of injury and death of Aboriginal people under 25 years of age (Pike et al., 2010). With the aim to better understand and reduce the risk of injuries and fatalities from all manner of vehicles, Angell's prevention initiative in collaboration with researchers and First Nations, Inuit and Métis peoples and communities is geared to address this gap in knowledge and to create conversations within Indigenous peoples about how best to respond in partnership to deal with these ongoing challenges.

The British Columbia based members of the research network team aimed to 'travel together' with ISICUE and partnering Indigenous communities in theory, method, and practice to raise awareness about ongoing transportation safety concerns. Guided by Angell's research leadership on the AUTO21 funded project, the partners at Tsawout First Nation, and the ISICUE transportation safety research team included Director Dr. Leslie Brown, Postdoctoral fellow Dr. Sarah Marie Wiebe, graduate research assistants Kelly Aguire and Amy Becker from the University of Victoria and community research assistant Israyelle Claxton from Tsawout. The local research team organized transportation safety-themed events, which included collecting community experience with aspects of transportation safety and feedback about local transportation safety concerns. A community conversation format provided a useful foundation for the development of locally-situated PAR initiatives. In Tsawout, this process facilitated the visibility of the British Columbia-based research team in the community and raised awareness and curiosity on the topic of transportation safety, while creating an inviting atmosphere of engagement. As we discuss in the next section, in the Tsawout First Nation, with the support and mentorship of community-based research assistant (CRA) Israyelle Claxton, we concentrate on some of the issues related to youth safety through a participatory video project organized on the theme of "Light up the Night." In addition to making the British Columbia-based research team visible as partners through the community conversation process, we too sought to assist the community with their own vision of brightening up their streets to make them safer, more accessible, and more enjoyable. Using participatory tools, during this process the community was involved in all stages of research engagement from design to knowledge dissemination.

In accordance with ethics and protocols of dignity and respect, the BC-based research team began its outreach in connection with our existing relationships and affiliations with Indigenous leaders from the First Peoples' House. Early in 2014, we called a meeting to discuss an appropriate strategy to engage Indigenous partners in a conversation about vehicle safety and injury prevention. During the meeting, hosted by the Office of Indigenous Affairs at the University of Victoria, we agreed to invite local community representatives to a lunch gathering at the Songhees Wellness Centre. Tsawout First Nation was one of the communities 
whose members attended and expressed interest in being a part of the collaboration. From there, the BC-based research team began to meet with community representatives to determine how the research would be conducted and what protocols would be followed. As part of the discussion, the community members were informed of the intention of the project to engage the people in the communities on ways to reduce the risk of vehicle-related injury and death using their expertise and vision. Designed collaboratively, the project reflected the needs of the community and their insight and knowledge to plan a way forward. This necessitated a discussion of time and resources needed to make the project a success. The funding subgrant from Angell's AUTO21 research award enabled the hiring of the graduate student researchers to work with the community on the project and paid for travel costs. Additionally, Angell provided 20 child booster seats for participating communities through the Children's Safety Project Trust Fund (CSPTF), which he established at the University of Windsor. These stateof-the-art child booster seats were distributed to families in Tsawout as part of the project during a community conversation event.

\section{Lighting up the Night in Tsawout First Nation with Participatory Video}

STÁUTW (Tsawout) is home to approximately 749 people and is part of the WSÁNEĆ (Saanich) Nation with territory centred on the Saanich Peninsula and southern Gulf Islands (First Peoples' Language Map, 2015). Their territory includes land and water (Claxton, 2014). The WSÁNEĆ (Saanich) First Nation is a single Nation that was historically split into four First Nations according to the imposed village site by the Canadian government. In 1850, colonial authorities in London, UK, appointed the Hudson's Bay Company to establish a colony on Vancouver Island (Tsawout First Nation, 2015). At this time, colonial authorities saw these lands as empty of law and jurisdiction and thus rendered the importance of Indigenous peoples and their relationships to their lands and resources invisible. James Douglas completed 14 purchase agreements with Vancouver Island Indigenous nations, which are often referred to as the "Fort Victoria Treaties" or "Douglas Treaties" (Tsawout First Nation, 2015). As Tsawout member and Indigenous scholar Nick Claxton articulates, colonial authorities and Indigenous peoples had very different understandings of what these treaties meant and how they would be applied (Claxton, 2015).

Today, the STÁUTW (Tsawout) First Nation, also known as Indian Reserve No. 2, is centrally located on the east side of the Saanich Peninsula, approximately $20 \mathrm{~km}$. north of the City of Victoria. The community runs municipal services including a capital structure for sewer services. The community's territory also includes lands and waters on the Gulf Islands including Saturna, Pender, and Saltspring. Their territories include single family residential as well as leased manufactured, or prefabricated homes. Other buildings include band, community and commercial developments such as motels, restaurants, offices, and gas stations (First Peoples' Language Map, 2015). Pat Bay Highway \#17 splices through the reserve's 595 acres reserve land base.

After several planning meetings, it became clear to the British Columbia research team from their discussions with Indigenous partners that youth engagement was a priority for the 
people of Tsawout. We worked closely with the community-based research assistant who was recommended by the community's health department. She skillfully facilitated the interactions between the partners during a time of community restructuring and transitioning. Early on we agreed on the importance of creating an atmosphere of engagement in order to produce research-based meaningful promising practices with lasting impact for the community as well as for the academic community. During our initial meetings, we assessed different research processes and it soon became clear that in order not to become what community-based research assistant Israyelle Claxton referred to as a "flash bang" project—an extractive model of knowledge gathering where researchers merely drop into a community, collect data and leave-relationship-building over time would be crucial. To avoid the prospect of falling into the described historical model of researchers doing hit-and-run style research, the $\mathrm{BC}$ research team decided to support the community through a series of participatory video workshops.

We continually negotiated between the parameters of project administration and community approaches to CER. Initially, our funding for participatory action aimed to support graduate student development as "highly qualified personnel"-language created by the Natural Sciences and Engineering Research Council of Canada (NSERC) — which did not include budget support for food or for associated project costs. Collectively, we had to be innovative - including Dr. Brent Angell's success in securing funds from the First Nations Children's Safety Project Trust Fund - to meet the project's needs, which involved fundraising to hire a community-based research assistant. We will discuss this as one of our significant challenges in the concluding section. During our frequent research team meetings, the theme of youth leadership and community safety emerged. Soon, the "Light up the Night" project began to take shape in Tsawout First Nation.

We employed participatory video (PV) techniques and principles to engage a group of Tsawout youth with the subject of transportation safety in their community. We had originally hoped to engage a group of youth around driving age (16 years of age in British Columbia). Israyelle and her colleagues suggested this process might result in a video that could be used as a public service announcement, available on the Nation's website and periodically displayed on their electronic notice board in the community centre lobby. Based on past experience using video as a means for creative community engagement, our team considered PV a relevant, fun, and exciting method for the PAR portion of this project. PV is often publicized for its action-oriented nature as a means for deeper involvement in the CER processes, its low-cost and ease of use of film equipment, and its high-impact materials, especially in the age of the Internet (Benest, 2010; Lunch \& Lunch, 2006; Tremblay \& Jayme, 2015; White, 2003). The PV process, we expected, would engage local youth in the subject of transportation safety while also developing their skills in digital video creation. Moreover, there would be a digital product for the community to use afterward, and our team could report on the insights we gained from the PV process. Finally, we expected the PAR/PV process had the potential to enable local, community-based action and change on the issue of high incidences of transportation-related injuries and death among Aboriginal people and on-reserve.

Our PV process took on an experimental quality as challenges and opportunities arose. 
Some of the challenges we faced were an initial lack of interest from youth (despite keen community leaders' interest), project timelines and budget constraints. We adapted to these challenges with a flexible atmosphere of engagement, collaboration and enjoyment created by the research team, and the youth and the community leaders who supported the project. We found that by doing this a younger group of children interested in vehicle safety and injury prevention emerged.

In the early stages of project design, our community partners identified youth as an important group to reach in our project. In addition to weekly filming workshops that ran in conjunction with the Nation's weekly youth night, we held an event called "Light up the Night." The event included the screening of our first video, which was an advertisement for the "Light up the Night" event, created during the previously held weekly PV workshops with youth. The event also included food, activities such as community mapping and bike decorating, and the filming of another video Don't Text and Drive: SLALE $H A U_{s} E$ (Safe Travels)—a public service announcement about the dangers of distracted driving. At a later date, we facilitated a community conversation with 10 interested adults about the subject of transportation safety,

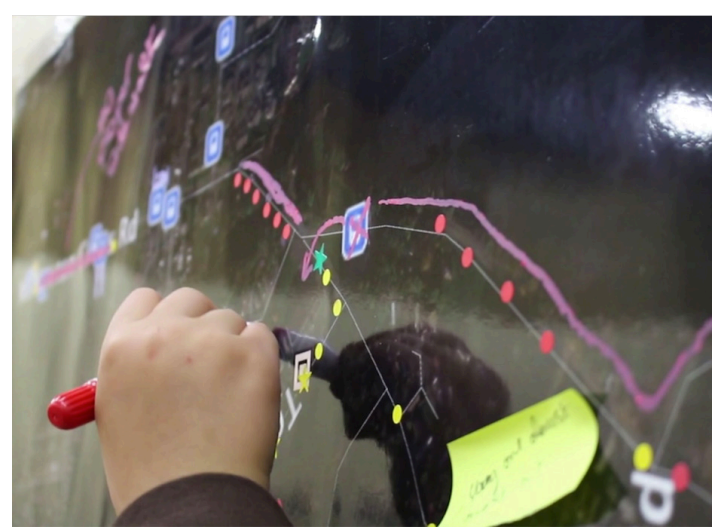

Figure 1: Tsawout youth mapping which also informs our analysis. What follows is an overview of, and critical look at, participatory video as a method for community empowerment and action as well as a discussion of how our PV process unfolded and what we learned about the Tsawout community's transportation safety concerns during the process.

Participatory video projects typically involve collaboration between the research team or PV practitioners and a community group with particular needs and concerns. In the same way that PAR projects involve collaborating with communities at all stages of the research process, a PV project is often considered ideal or successful if community members participate in, collaborate on, and take ownership of each step of their story and video creation. Based on popular PV guidelines (see Benest, 2010; Lunch \& Lunch, 2006), the research team guides community members through five main steps: (1) idea formation, (2) storyboarding, (3) shooting (filming), (4) editing, and (5) screening and dissemination. We used this PV model as a guide for our workshops and events; however, some aspects of these guidelines were more engaging than others to the youth involved, and it seemed that a less-structured approach was preferable within the context of this project.

For the filming workshops, or PV sessions, the community-based research assistant arranged for our research team to drop-in on the Nation's youth night at the local community centre. Youth night, during the six weeks that we dropped in, was characterized by youth 
of all ages, mostly male, playing group sports in the local gymnasium. The Nation's youth coordinator supported us by gathering the youth for us to pitch the idea of making a video about transportation safety in their community. During our first session, we played ice-breaker games and facilitated a few standard PV exercises to familiarize the youth with the cameras. Several youth at the end of our first session expressed interest in learning to shoot and edit video; however, their interest waned by the next session. We tried to keep our presence consistent by attending youth night every week for the following five weeks, during which we facilitated filming activities in a room adjacent to the gym. This also meant that the youth could participate some days and not others, based on their interest. We felt that this would be an appealing, flexible approach that would allow for new participants as time went on; however, we found that the same five or six youth, between the ages of 8 and 12, attended the workshops or opted-out on any given day.

Participatory video is often described as a research process that has empowering effects, particularly on marginalized people (Benest, 2010; Lunch \& Lunch, 2006; Kindon, 2003; White, 2003). Cited benefits of PV include building capacity and community cohesion, engaging and giving voice to individuals who have historically been silenced, and developing culturally relevant visual and aural representations of the experienced life (Benest, 2010; Lunch \& Lunch, 2006; Kindon, 2003; White, 2003; Willox et al., 2013). Kindon (2003) argues that

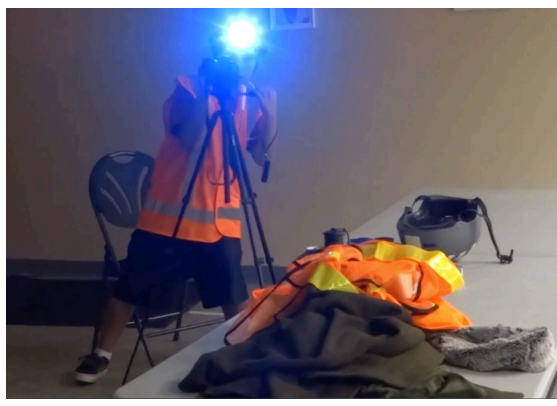

Figure 2: Tsawout youth videographer, Light up the night. PV approaches to community-based research are a way for researchers to "'speak nearby' rather than 'speak for' less powerful Others in their research processes" (p. 149). It is hoped that PV processes create change, especially when the videos made by community members are used to communicate with policy makers about their experiences in the world (Kindon, 2003).

Recently, however, scholars have become critical of the idealized, and often sensationalized, emancipatory power of participatory principles (Cooke \& Kothari, 2001; Walsh, 2014). Milne et al.'s (2012) Handbook of Participatory Video encourages us to interrogate the often-circulated assumptions of participatory video's empowering nature and ability to bring about social change. As High et al. (2012) point out; the emancipatory effects of participatory video have not yet received much study. Indeed, Mistry et al. (2014) argue that "to date, there is little evidence in the literature that communities themselves are the primary champions and users of participatory video" (p. 6). Quite simply, there can be logistical challenges to "equal" participation between the community and researchers. As Wiebe (2016) points out, participatory practitioners must remain continually aware and adaptive to community realities, notably that community participation is time and resource intensive. There are also theoretical assumptions underlying participatory principles that merit reflection. Walsh (2014), a participatory-video practitioner herself, argues that the notion of having disempowered people "speak for themselves" to 
achieve empowerment is an unquestioned liberal assumption underlying the ideals of PV, which may be more patronizing than emancipatory. Furthermore, Low et al. (2012) argue that studies in PV "seem to equate the subject's participation with her agency-that is, her participation is seen as both the evidence and the actualization of an agentic self" (p. 55). The assumption then becomes that empowerment and social transformation follows necessarily from participants' expressions of agency within PV projects.

When taking a more critical eye to PV practices, it is clear that PV is not a neutral process whereby participants' voices and interests are uninhibited: PV is more often a negotiated relationship that must attempt to balance the interests of the researchers with the community as well as the varying interests within the community itself. It is not uncommon for tension to exist between the goals of an organization (and funder) and the interests of PV participants, and this kind of tension is an example of the ways in which participation is negotiated and mediated in participatory research (Low et al., 2012).

This continually negotiated relationship influences the kinds of participation that occurs. The previously established transportation-safety theme of this PV project, for example, was a factor influencing Tsawout youth's participation in the project, no matter how creative we tried to be around the subject. Our first insight into Tsawout youth's perception of transportation safety, perhaps unsurprisingly, is that transportation safety is not the most engaging topic for youth around driving age. None of the older youth present at youth night volunteered their time to work on the PV project, perhaps not only because of the subject matter but also because being involved would mean less time playing sports. Even the younger group of participants who were involved did not engage as strongly as we had hoped with forming a story about their experience with transportation safety in their community. However, after having already consulted with several potential community youth leaders, and considering the limited timeline of the project, we decided to move forward with the youth night strategy despite the younger age range of interested kids and their lack of interest in the subject. Thus, our research team took more leadership in visioning for the videos while the youth participated in acting, directing and learning how to use the equipment. The research team's strong participation in story formation was perhaps flawed when considering an idealized PV project in which there is equitable participation and participants take strong ownership of telling a story.

Scholars point out that there is great diversity in the projects that fall under the label of "participatory video." Indeed, High et al. (2012) argue that "there is no common understanding of participatory video" (p. 35). Mistry and Berardi (2011), for example, define participatory video as "a process involving a group or community in shaping and creating their own films according to their own sense of what is important and how they want to be represented" (p. 110). Other definitions add non-negotiable criteria, such as "enabling positive change and transformation" (InsightShare, "Values and Core Charter"). But High and Nemes (2008) prefer a more broad definition, simply that PV is about " $[\mathrm{m}]$ aking films with people for social learning" (qtd.in High et al., 2012, p. 41). They emphasize with as opposed to about in their definition, and assert that PV "can be very generally conceived as filmmaking that includes its 
subjects, and others, in the creative process" (High et al., 2012, p. 41; Tremblay \& Jayme, 2015). They point out that the more difficult phenomenon to assess according to this definition is whether social learning occurred. But they argue their open definition is based on the history of PV, which is characterized not by a single methodology but diversity "that emerges from the openness to difference and innovation" (High et al., 2012, p. 41). What's more, they advocate for an emphasis on "skills and values" in order to "keep the nature of participatory video open and experimental while still reserving space to make judgements about good participatory video practice" (ibid.).

Kindon (2003) argues that PV should equally position the researcher and research participants in front of and behind the camera, "symboliz[ing] a degree of destablization of conventional power relations in the research relationship and of particular claims to the unquestioned transparency of the image" (p. 146). Our research team was significantly present as participants during this PV project. Our first video shoot was an experimental and experiential atmosphere that blended learning to use the filming equipment, acting in front of the camera, and playing with reflectors and lighting to find fun ways to light yourself up as a pedestrian at night, all the while documenting the participatory process. Roles (actor/camera operator/director) were decided in the moment as the youth told us what they were interested in. Our strategy that night was to bring plenty of transportation safety-related props, cameras, tripods, a few ideas of what we could shoot, and see what emerged. Together with the youth, we experimented with filming the effect of glow sticks, glow-in-the-dark tape, and flashlights decorating helmets, skateboards and bodies in a dark room. The final video from this shoot was a montage of clips from that night, showing everyone, researchers and participants, behind and in front of the camera, with an overall aesthetic that highlighted how lighting yourself up at night can be a fun and creative thing to do. Although the youth displayed a general lack of interest during the editing phase (besides the choice of background music), we decided to use the footage from this fun night of filming as an advertisement for the subsequent "Light up the Night" event. We put on the "Light up the Night" event to try to engage more youth and adults in the one-day creation of a more structured transportation-safety public service announcement, the storyboard of which our research team created before the event.

While there may not have been strong youth ownership of story and idea formation for either of the videos, our visioning of "Light up the Night" was supported by feedback from Israyelle, other community members, and the youth. Early on, Israyelle made it clear that dark streets were a well-known safety issue in the community, and this concern came up time and again in our conversations with youth and adults during the filming workshops as well as during the "Light up the Night" event and the community conversation. Working with younger youth brought our attention to pedestrian safety in relation to dark streets because primary modes of independent transportation for children and youth were walking, skateboarding and biking. This was particularly true for access to the community centre where youth night and our filming sessions were held. Because we were concerned with social learning and actionable outcomes, as well as the creation of a public service announcement, we focused on mobilizing a message about what individuals could do to prevent transportation-related injury. Thus, our 
first video, the event advertisement, focused on individuals making themselves visible at night. At the "Light up the Night" event, in response to community feedback, our team decided to move our attention from pedestrian responsibility to driver responsibility, and we then filmed a story about the perils of distracted driving.

Particularly when working with children and young people, and in the context of creating a public service announcement that includes an achievable call to action, our research team focused on story formations that moved back and forth between issues of pedestrian responsibility and driver responsibility. However, as we discuss in the next section, our conversations with adults, parents, and caregivers at the "Light up the Night" event and during the community conversation shifted attention from individual driver and pedestrian responsibilities and highlighted the interface between the two: infrastructure-sidewalks, bus routes, street markings, signage, etc. This raises crucial questions about responsibility for transportation safety within Indigenous communities. The responsibility of pedestrians to be visible at night and take the necessary safety precautions when riding bikes and skateboards, and the responsibility of drivers to buckle up and avoid distractions were clearly important and necessary responsibilities to promote according to Tsawout members. But, as we next discuss, a lack of necessary road safety infrastructure was just as important, and greatly impeded access to community events and the independence of children in the neighborhood. As one community member said, "We want our children to be independent, not scared to walk around" (Nadine, personal communication, March 30 $\left.{ }^{\text {th }} 2015\right){ }^{1}$

\section{Traveling Through or Traveling Together?}

On March 30, 2015, we hosted a community conversation and lunch in Tsawout to share the PV work we had done to that point, distribute booster seats to families, and facilitate a focused discussion on transportation safety. As noted, infrastructure (road lighting, markers, signs, sidewalks) and the practicalities of day-to-day travel (such as pedestrian interactions with vehicular traffic, especially youth endangerment) emerged as major concerns (Community Conversation Participants, March 30, 2015). However, complex questions also began to emerge concerning the fundamental causes of traffic conditions on reserves. It seemed necessary to account for these questions in our discussion of improving community safety and promoting conditions for injury prevention. Uncertainty about accountability and jurisdictions came to the fore regarding, for example, responsibility for transportation safety awareness initiatives as well as resource development and availability for such initiatives and infrastructural upgrades.

Much of the community observations and feedback seemed to ask: "Who is responsible for transportation safety in Tsawout?" What may have originally appeared as a straightforward and narrow track of inquiry expanded in response to the contextual particularities of the Tsawout community. This PAR project began to resist the institutional or structural constraints that still lead many community-engaged researchers (often unwittingly) into "flash-bang" dynamics. Discussing how to improve transportation safety in Tsawout raised broad questions

1 Pseudonyms are used here to maintain the privacy of Community Conversation participants. 
of accountability and governance, relationships with surrounding communities, and land-use and development. It became evident to us that transportation safety or vehicle safety are not isolatable issues with straightforward avenues for amelioration. For example, while important, attempting to decrease vehicular-related injuries through the promotion of generalized safety device skills and traffic awareness at the level of individuals, families or even the community does not address the sources of heightened endangerment for First Nations people or Tsawout members in particular compared to the general Canadian population. Such initiatives may be considered a symptomatic or mitigating approach to complex issues that manifest as incident or accident statistics.

Themes arising in the project resonated with us as appropriate metaphors for some challenges we found in navigating CER relationships responsibly. Sometimes it seemed we were aiming for a predetermined destination along frequently intersecting, often dimly illuminated or unclearly marked routes, with a map and set of road rules that didn't quite match the layout and patterns of movement on the ground. An example of this is the basic terms of the broader research project we were a part of. A premise as seemingly straightforward as vehicular injury prevention and safety in Tsawout is immediately complicated by the realities of permeable reserve boundaries; travelling on, off, around and through the reserve is complicated by attitudes toward safety that change when those boundaries are crossed. They act as filters.

In our community conversations, we listened to stories of how accidents and "near-misses" with pedestrians frequently involve non-member drivers treating the reserve as a kind of physical and metaphorical zone of permissibility. As voiced by several community members, this kind of attitude is influenced by road-safety infrastructure: "There are no lines dividing the road, so that kind of creates a free-for-all mentality" (Rose, personal communication, March 30, 2015); another community member said: "Drivers don't have the same courtesies that they would have off-reserve" (Charlie, personal communication, March 30, 2015). Here, any consideration of promoting traffic law and safety awareness in Tsawout confronts jurisdictional uncertainty; for example, due to uneven infrastructure standards on and off-reserve, a common-sense particular to Tsawout regarding safety and how these factors of mobility (how we move and what moves with us) implicate larger relations of privilege. The question then becomes who is the community of responsibility for transportation safety in Tsawout?

The project also required us to navigate by multiple, fluctuating, and at times seemingly competing codes of communication, conduct and expectations for research outcomes. This arose from range of factors as varied as mid-project staff-turnovers and the difference between the formality of academic training and on-the-ground community expertise. Varying codes of conduct include those of the community (through its liaisons, governance structures, etc.), the research leads and funders, the University of Victoria and ISICUE, individual research participants, as well as other governments and agencies like surrounding municipalities and the Royal Canadian Mounted Police (RCMP). Despite the functionality of instruments like the project research agreement between the Tsawout First Nation, ISICUE and the University of Windsor to ensure mutual understanding and continuity, and provide guidance, the right of way was not always immediately apparent. However, our commitment to OCAP principles 
suggested that any balancing of interests at moments of uncertainty should err on the side of community needs and protocols in keeping with this rootedness in PAR ethics. Conducting ourselves in a good way requires identifying to whom we must defer at different junctures in the project. This in turn necessitates judging the appropriate lines of accountability and understanding how they are drawn and are to be followed in those circumstances. For example, at one point in the project a challenge arose for the BC-based research team that stemmed from contrasting desires and expectations between the community and the funding body. Revisiting the primacy of the WS'ANEC' - University of Victoria Collaborative Agreement helped the team to be guided by the best interests of the ongoing relationship between Tsawout and ISICUE. Thinking in terms of relationship and keeping the past and future of that relationship alive in the present research project is in keeping with a protocol of dignity (Thomas \& Brown, 2015).

For a CER research team that initiates and sustains direct relationships with/in the community, proximity and a range of methodological and experiential backdrops affect our personal sense of accountability. We are the faces, hands and voices of the project and act as conduits between the community and university. We acutely perceive and shoulder the immediacy of any theory/practice disjuncture and manage the minutiae of collaboration. We have to gauge and be responsive to what is workable or essential for maintaining successful partnerships on the ground, mostly by trial and error. As already mentioned, an example from our experience with event-planning and PV workshops in Tsawout required creative solutions to address spending restraints of the project set by the funders, which did not entail provisions for community meals and refreshments. These are crucial and culturally important gestures of hospitality in Coast and Straits Salish territories. As we learned, to display and portray intentions of reciprocity, when a researcher approaches a community with an expectation for knowledge exchange and in pursuit of making a meaningful connection, certain hospitality protocols are imperative. We certainly noticed that having locally catered food available created a welcoming atmosphere for community members to speak with us and learn about the project. There are also general considerations for ensuring the comfort of participants (especially youth and elders) in research activities who may be choosing between these and other priorities, which might interrupt their daily routines including mealtimes. The BC-based research team knew what protocols were regarding the sharing of food and thus made efforts to make sure these protocols were followed so that all participants were respectfully invited and included. It is arguable that the principles of access and equitable participation might have been compromised otherwise.

Perhaps the greatest overarching lesson, if not learned then reinforced through our project with Tsawout, is one which Indigenous thinkers on methodology and research ethics have expounded on eloquently for a long time. This is the fundamental appreciation of and responsiveness to community distinctiveness, their situated knowledges and land/placebased perspectives as well as a corresponding account of self-location in the research design (Strega \& Brown, 2015). We cannot engage in projects as interchangeable vehicles carrying interchangeable passengers through interchangeable space. Furthermore, it is critical that 
researchers treat community members as experts to inform the project's overall structure and are responsive to their research needs.

Insofar as proceeding from community relevance, the team had to generate interest in the theme of transportation safety for the PV workshops as it was predetermined, rather than selfdetermined by participants. Researchers who bring projects to communities rather than the reverse can shift energies, regardless of those projects' adaptability. Several adult participants suggested that transportation safety, especially pertaining to children and youth, is an important concern but one that had been previously overlooked as a health and wellness priority among others that appear more pressing. We did hear that there was an appreciation of the opportunity to generate community dialogues about their connections, with one elder sharing that she had never heard of a similar initiative in the community before that got the attention of youth like her great-grandchildren (community conversation participants, March 30, 2015).

Finally, how did and can we apply the concepts of action and change in this CER process? Despite the possible critique that the idealization of an emancipatory promise in PAR projects may replicate liberal paternalism, our creative collaboration has shown their potential as a stillrelevant approach toward transforming institutional research relationships with Indigenous peoples. However, at the same time, this hinges on more movement to shift our thinking about collaboration and projects; that is, regarding their purpose, assessment, trajectories and ends. Establishing continuity and incorporating capacity-building support for the community to sustain and grow initiatives that show traction is crucial, whether they veer down other roads or the journey exceeds intended timelines (they always will). To continue to grow this work and enhance the likelihood of the project's sustainability, through crowdsourcing at the University of Victoria's "100 People who Care" initiative, our research team was successful with securing funding to support the community-based research work and to address the critical question of: Who is responsible for transportation safety in Tsawout?

\section{Conclusion}

We must situate ourselves and be mindful of the legacies of extractive research relations between academia and Indigenous communities in any effort to avoid the replication of these methodologies. We are all travelers from different directions, responsible to where we come from, where we are and where we are going and how we engage when our paths meet. This is where we decide, are we simply travelling through? Or are we travelling together? We must begin to take seriously what that distinction may really mean.

Distracted driving ended up being the subject of our public service announcement-style video, which involved youth in the community in order to speak about a critical issue. At the same time, it is an apt metaphor for the demeanor that many academics are perceived to have when entering communities, distracted by administrative parameters and time constraints mandated by the traditional funding cycle, which can affect the time needed to build and maintain relationships.

Finally, in conclusion — which we conceptualize as an invitation to further conversation 
rather than a form of closure-we will shed light on three key challenges that emerged during our collaboration. First, we needed to be more mindful of how to ensure and secure adequate resources to support our CER initiatives whether they be personnel or material (i.e. camera gear, projector, sound equipment, food, meeting space, etc.). Funding constraints and planning require creative planning and implementation to ensure the success of any research, particularly PAR projects that are community driven and variable from site to site in terms of requirements. The standard university ethics and grant administration protocols often mean that the authority for dispersing project funds rests within the academy rather than the community. Second, like many kinds of relationships, community partnerships are continually shifting. Transitions in community governance prompted our research team to also adjust accountability structures in order to accommodate for changes in pre-established staffing positions at the community centre. Given our research team's grounding in the WS'ANEC' - University of Victoria Collaborative agreement, we acknowledged the importance of continuing to follow through on our commitments to the community despite turnover in leadership. In this way, we see our research ethics as more than a document about protocols but fundamentally about cultivating long-lasting relationships, which may extend beyond the research project's anticipated end date. Third, in the final stages of our project, it became clear during our community conversation that developing a better understanding of jurisdiction for critical infrastructure - that is, who is responsible for Indigenous people's transportation safety and Tsawout's in particular-became a significant question. In response, we used our funds crowdsourced from the "100 People Who Care" initiative to continue working with Israyelle and to highlight transportation safety concerns local to Tsawout and co-produce a mini-documentary that includes the voices of band officials and representatives from the Greater Victoria Capital Regional District.

Our experiences with PV suggest the need for its processes to be adaptable to community dynamics. We learned many lessons along the way. Although the youth did not take a strong ownership of the story formation during the early phases of our research design, social learning occurred as community members perceived the PV process and the "Light up the Night" event as innovative and engaging processes. Going forward, as collaborative researchers, we acknowledge our responsibilities to foster critical conversations about action and change that are rooted in community perspectives. These responsibilities are ongoing and last beyond the project end as we continue to learn about how to work and travel together, rather than traveling through communities, now and into in the future. 


\section{Acknowledgments}

Situated on Coast and Straights Salish territory, our interdisciplinary Research Team includes scholars from the faculties of Human and Social Development and Social Sciences at the University of Victoria in addition to the Tsawout First Nation in partnership with the University of Windsor. This project was made possible through support from the Auto21 Network and the leadership of Dr. Brent Angell, Professor of Social Work at the University of Windsor. We would like to acknowledge all of the dynamic research participants and partners from the Tsawout First Nation across the generations.

\section{About the Authors}

All members of the Research Team have extensive experience working with Indigenous communities, share an interest in social justice and apply arts-based methodologies to the practice of decolonizing research.

Kelly Aguirre is a PhD Candidate in the Department of Political Science at the University of Victoria whose research is centred on the representation of Indigenous practices of self-determination and the ways resurgence implicates a decolonization of knowledge (re) production around these practices.

Brent Angell is a professor of Social Work at the University of Windsor. His scholarly interests focus on redefining critical perspectives related to diversity and community practice. Dr. Angell collaborates with a number of Canadian First Nations on research related to health and safety.

Amy Becker Amy Becker is a MA student in the Department of Anthropology at the University of Victoria collaborating with the Stz'uminus First Nation on a project called "Stz'uminus Storied Places," a digital mapping and oral history project.

Leslie Brown is the former Director of the Institute for Studies and Innovation in Community University Engagement at the University of Victoria and a recently retired professor in the School of Social Work. She has published widely on the topic of transformative research and ethical engagement with Indigenous communities.

Israyelle Claxton is a community leader, organizer and transportations safety enthusiast from the Tsawout First Nation. 
Sarah Marie Wiebe (corresponding author) is an assistant professor in the Department of Political Science at the University of Hawai'i, Manoa. She previously held a SSHRC PostDoctoral Fellowship with the Institute for Studies and Innovation in Community University Engagement at the University of Victoria. Her research focuses extensively on environmental justice, policy dialogue and creative forms of engagement including photography and filmmaking. For further information, see: http://www.sarahmariewiebe.com.

\section{References}

Angell, G. B. (2012). Understanding and reducing the risks of vebicle-related injury in First Nations, Métis, and Inuit communities. Unpublished research proposal submitted to AUTO21.

Benest, G. (2010). A rights-based approach to participatory video: Toolkit. InsightShare. Retrieved from http://insightshare.org/resources/right-based-approach-to-pv-toolkit.

Carrier Sekani Family Services (2006). Highway of tears symposium recommendations. Report. June 16. Retrieved from: http://highwayoftears.org/uploads/Highway $\% 20$ of $\% 20$ Tears $\% 20$ Symposium\%20Recommendations\%20Report\%20-\%20January\%202013.pdf.

Claxton, N. (2014). To fish as formerly, University of Victoria Community Mapping Collaboratory. Retrieved from https:/ /www.youtube.com/watch?v=vTQk1IR9ibc

Cook, B. \& U. Kothari (Eds). (2001). Participation: The new tyranny? Zed Books: London \& New York.

Durbin, DR (2011). Committee on Injury, Violence and Poison Prevention. Child passenger safety. Pediatrics, 127(4).

First Peoples' Language Map of British Columbia (2015). Retrieved from http://maps.fphlcc.ca/ stautw.

Haraway, D. (1988). Situated knowledges: The science question in feminism and the privilege of partial perspective. Feminist Studies, 14(3), 575-599.

Health Canada (2001). Unintentional and intentional injury profile for Aboriginal people in Canada. Ottawa: Public Works and Government Services Canada.

Health Canada (2007). Canadian injury data: Leading causes of death and hospitalization in Canada. Ottawa: Public Works and Government Services Canada.

Health Canada (2011). A statistical profile on the health of First Nations in Canada: Vital statistics for Atlantic and Western Canada, 2001/2002, First Nations and Inuit Health. Retrieved from http://www.hcsc.gc.ca/fniah-spnia/pubs/aborig-autoch/stats-profil-atlant/index-eng.php\#a635

High, C., Singh, N., Petheram, L., \& Nemes, G. (2012). Defining participatory video from practice, pp. 3545. Retrieved from http://www.methodspace.com/video/what-is-participatory-video-by.

InsightShare. (N.d.). Values and core charter. Retrieved from http://www.insightshare.org/about-us/ charter.

Kindon, S. (2003). Participatory video in geographic research: A feminist practice of looking? Area, 35(2), 142-153.

Engaged Scholar Journal: Community-Engaged Research, Teaching and Learning 
Leitch, K. (2007). Reaching for the top: A report by the advisor on healthy children and youth. Ottawa: Health Canada.

Low, B., Brushwood Rose, C., Salvio, P.M., \& Palacios, L. (2012). (Re)framing the scholarship on participatory video: From celebration to critical engagement, pp. 49-64, in Handbook of Participatory Video. Lanham: Rowman \& Littlefield Publishers, Inc.

Lunch, N., \& Lunch, C. (2006). Insights into participatory video: A handbook for the field. Oxford: InsightShare. Retrieved from http://www.insightshare.org/resources/pv-handbook.

Milne, E-J., Mitchell, C., \& De Lange, N. (Eds.). (2012). Handbook of participatory video. Lanham: Rowman \& Littlefield Publishers, Inc.

National Aboriginal Health Organization (NAHO). (2005). Ownership, control, access and possession (OCAP) or self-determination applied to research, First Nations Centre. Retrieved from http://www.naho.ca/documents/fnc/english/FNC_OCAPCriticalAnalysis.pdf

Ochocka, J. \& Janzen, R. (2014). Breathing life into theory: Illustrations of community-based research hallmarks, functions, and phases. Gateways: International Journal of Community Research and Engagement, 7, 18-33.

Pike, I., McDonald, R., Macpherson, A., et al. (2010). Developing injury protection indicators for First Nations children \& youth in Canada. Vancouver, BC: UBC.

Pike, I., et al. (2010). Injury protection indicators for Inuit children \& youth. Ottawa, ON: First Nations and Inuit Children and Youth Injury Indicators Working Group.

UNICEF Canada (2009). Canadian supplement to the atate of the world's children 2009 - Aboriginal children's health: Leaving no child behind. Retrieved from http://www.unicef.ca/sites/ default/files/imce_uploads/DISCOVER/OUR\%20WORK/ADVOCACY/DOMESTIC/ POLICY\%20ADVOCACY/DOCS/Leaving\%20no\%20child $\% 20$ behind $\% 2009$.pdf

Statistics Canada (2011). Leading causes of death (both sexes), Summary Tables. Retrieved from http://www.statcan.gc.ca/tables-tableaux/sumsom/101/cst01/hlth36a-eng.htm

Strega, S. \& L. Brown, (Eds.) (2015). Research as resistance. $2^{\text {nd }}$ ed. Women's Press: Toronto:

Thomas, R., \& L. Brown (2015), Protocols of dignity, conference presentation, CUExpo, Ottawa.

Transport Canada (2000). Keep kids safe: Car time 1-2-3-4. Retrieved from http://publications.gc.ca/ collections/collection_2012/tc/T46-27-2001-eng.pdf

Transport Canada (2004). NORP annual monitoring report. Retrieved from http://ccmta.ca/images/ publications/pdf/norp_report04.pdf

Tremblay, C. \&. B. Jayme (2015). Community knowledge co-creation through participatory video. Action Research, 13(3), 298-314.

Tsawout First Nation (2015). Douglas Treaty. About Tsawout First Nation. Retrieved from http:// www.tsawout.com/about-tsawout/48-history-douglas-treaty

Tuck, E., Allen, J., Bacha, M., Morales, A., Quinter, S., Thompson, J., Tuck, M. (2008). PAR praxes for now and future change: The collective of researchers on educational disappointment and desire, in J. Cammarota \& M. Fine (Eds.), Revolutionizing education: Youth participatory action research in motion, pp. 49-83. Routledge: New York.

Walsh, Shannon. (2014). Critiquing the politics of participatory video and the dangerous romance of ;iberalism. Area.

Wiebe, Sarah. (2016). Everyday exposure: Indigenous mobilization and environmental justice in Canada's chemical valley. Vancouver: UBC press. 
Wiebe, S. \& M. Taylor (2014). Pursuing excellence in collaborative campus community research, National summit background paper. Waterloo, ON.

White, Shirley (2003). Participatory video: Images that transform and empower. New York: Palgrave MacMillan.

Willox, Ashlee Cusolo et al. (2012). Storytelling in a digital age: Digital storytelling as an emerging narrative method for preserving and promoting indigenous oral wisdom. Qualitative Research, 13(2),127-147.

Winston FK, Kallan MJ, Elliott MR, Xie D \& Durbin DR (2007). Effect of booster seat laws on appropriate restraint use by children 4 to 7 years old involved in crashes. Arch Pediatr Adolesc Med, 161(3), 270-275.

World Health Organization (2004). World report on road traffic injury prevention. World health day, WHO Road Safety.

World Health Organization (2012). The top 10 causes of death, Media Centre. Retrieved from http://www.who.int/mediacentre/factsheets/fs310/en/ 